\title{
Ergonomic evaluation of lighting from dental school clinics: a cross-sectional study
}

\begin{abstract}
Objective: To evaluate the illuminance levels of dental clinics of a Brazilian University.

Methods: Clinical facilities with the highest student / user flow (clinics A, B and C) were selected. The data were collected by a luximeter (Model THDL-400- Instrutherm/Brazil), from the main workbench (peripheral area), the workbench adjacent to the equipment (action area) and also the lighting provided by the reflector (intervention area). Data were subjected to descriptive statistical treatment (mean and standard deviation) and inferential for a level of significance of $\alpha=0.05(5 \%)$.
\end{abstract}

Results: Clinical facilities showed different mean values of illuminance for all the studied areas $(\mathrm{p}<0.05)$, with the highest values being attributed in the peripheral area for the $\mathrm{C}$ clinic (482,38 Lux) and in the area of action for the clinic B (550.88 Lux). Throughout the day, the majority of clinics had their luminosity statistically reduced. In relation to the intervention area, mean values of illuminance, with their respective standard deviations $( \pm)$, were 5208.14 Lux for clinical A ( \pm 393.44), 6468.21 Lux for B $( \pm 690,55)$ and 6871.11 Lux for C ( \pm 509.17).

Conclusion: The illuminance levels from intervention area of all clinical facilities presented values compatible with the parameters established by governmental regulations. However, the peripheral and action areas were far from ideal.

Keywords: dental offices, ergonomics, lighting
Volume 10 Issue I - 2019

\author{
Melissa Santos da Silva Simões,' Guilherme \\ Ricardo Pereira Santos,' Ana Laura lima de \\ Oliveira,' Pedro Romeu de Mendonça Vila \\ Nova,' Fábio Barbosa de Souza² \\ IDental School, Federal University of Pernambuco, Brazil \\ 2Department of Prosthodontics and Oral Facial Surgery, Federal \\ University of Pernambuco, Brazil
}

\begin{abstract}
Correspondence: Fábio Barbosa de Souza, Federal University of Pernambuco, Department of Prosthodontics and Oral Facial Surgery, Av. Prof. Moraes Rego s/n, Cidade Universitária, RecifePE, CEP: 50670-90I, Brazil, Tel +55-8I-2I 26-8830, +55-8I-99748237, +55-8I-2I 26-8344, Email fabiobdsouza@gmail.com
\end{abstract}

Received: January 28, 2019 | Published: February 06, 2019

\section{Introduction}

Ergonomics is the science that studies the relation of the human being to the work, trying to develop a perfect integration between the conditions of the environment, the capacities and physical and psychological limitations of the worker and the efficiency of the productive system. Its purpose is to increase human efficiency through logical decisions. In this sense, ergonomics acts in the removal of negative aspects of the work that in the long run can cause inefficiencies or the most varied types of physical incapacities. ${ }^{1}$ The difficulty in establishing a balance in the work-machine-environment trinomial has pointed to dentists as individuals vulnerable to occupational hazards. The Ergonomics applied to Dentistry has a fundamental role for the success of the actions developed during the dental care. Its objectives are: to rationalize work; eliminate non-productive steps; produce more and better; provide greater comfort and safety to the patient; obtain means and systems to reduce physical and cognitive stress; and prevent diseases related to dental practice, thus seeking a more expressive productivity. ${ }^{2}$ In this context, the ergonomic parameters related to the environment appear as decisive in maintaining the balance in dental work. In dentistry, lighting should be as appropriate as possible to ensure safety and health for the dental surgeon, since this professional belongs to a class that is at risk of eye trauma. This is due to the fact that, during his work, to fix the look in small details for a prolonged time, analogous problem of the typists. Consequently, you may blink less and get your eyes dry and burning, an injury called ciliary musculature spasm. ${ }^{3}$ Dental work requires motor coordination, reasoning, discernment, patience, safety, skill, delicacy, firmness and objectivity. Activities that together require a lot of the professional. In this way, adequate environmental parameters can make a difference in the performance of the work activities in a comfortable way and with the minimum of damages to the worker's body. ${ }^{1}$ In the scientific literature on the ergonomic parameters of the environment, studies that analyze the dental clinic are few. Thus, there is a need to carry out a study to evaluate this data in the workplace of the dentist, in order to identify and solve possible flaws. The present study evaluated the ergonomic parameters of illuminance of the school dental clinics of a Brazilian University.

\section{Methods}

\section{Design of the study and sample selection}

This investigation consisted of a cross-sectional quantitative, experimental and field research, carried out in the dental school clinical facilities of the Federal University of Pernambuco (UFPE), at Recife Campus, where data collection took place. The UFPE Dental School has 5 school clinics in operation (Clinic A, Clinic B, Clinic $\mathrm{C}$, Reception and Care Center, Clinic of Stomatology), which were considered the universe of the study. The selection of the sample used as inclusion criterion of the clinics with greater student/user flow. Thus, clinics A, B and C, which housed more than $90 \%$ of the clinical subjects at the time of the research, made up the research sample.

\section{Variables and data collection}

The records of the illuminance levels were performed at different locations, depending on the layout and number of work units within each school clinic. The illuminance data were collected from the main desk of all clinics (peripheral area), the workbench of the seven units selected for noise evaluation (area of action) and also the lighting provided by the reflector (intervention area), in which a distance of $80 \mathrm{~cm}$ from the light source was established as the standard of measurement. Figure 1 illustrates the distribution of data collection points in one of the school clinics, according to the variables studied. 


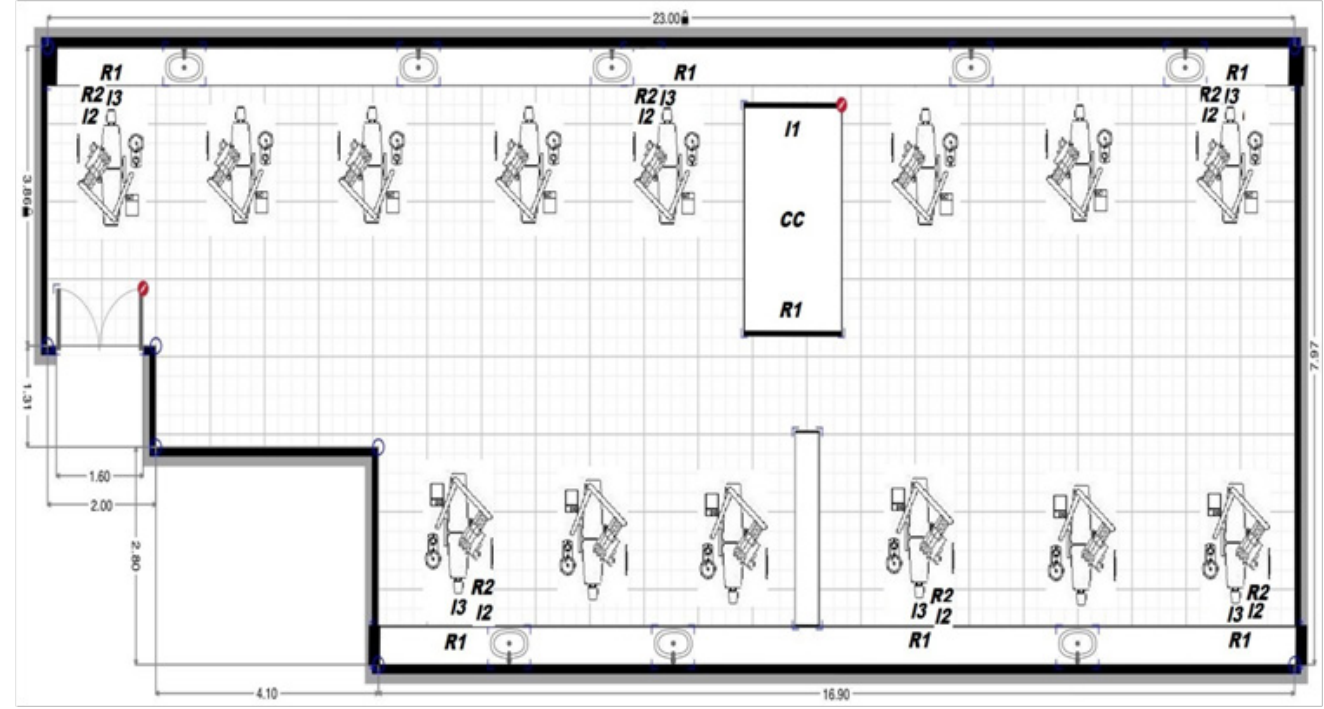

Figure I Spatial distribution of data collection points in Clinic C, of the UFPE Dentistry graduation, according to the variables studied. II - Illuminance peripheral area; 12 - illuminance - area of action; 13 - illuminance - intervention area.

For each clinic, collections were performed on seven different days. On each day, analyzes were performed on the shifts in the morning, late at night. For each shift, in the determined locations, three investigations were done at different times: 8:30, 9:30 and 10:30a.m. (morning); 1:00p.m., 2:00p.m. and 3:00p.m. (afternoon); 6:00, 7:00, 8:00p.m (night). The data were collected by a thermo-hygrodecibelimeter-lux meter - MODEL THDL-400 (Instrutherm/Brasil). The instrument used in the research had a calibration certificate. Measurement of the intensity of illumination was possible because the instrument has a silicon diode of high stability and long useful life with correction by the angular incidence of the light. The steps for collecting the illuminance data were: placing the function switch in the "lux" position; positioning of the photocell in a horizontal plane, according to the norm NBR 5413/92; Pressing the selection button to select the desired scale $(20,200,2000,20000)$; reading the nominal value on the LCD display; value in a specific worksheet. About the choice of scale, during collection, when the instrument showed only "1", it meant that the input signal was very strong, and a larger scale should be selected. And it was taken into consideration the national regulatory norm 17 of 2009 , which states that ideal for the peripheral area should be 500 lux, 1000 lux action area and 5000 lux intervention area.

\section{Statistical analysis}

The data obtained in each of the methodologies suffered descriptive statistical treatment (mean and standard deviation) and inferential treatment for a level significance of $\alpha=0.05(5 \%)$. The normality of the data was evaluated through the Kolmogorov-Smirnov and Shapirowilk tests. The comparisons between the values were performed through the tests: Analysis Variance, Tukey, Kruskal Wallis and Mann Whitney.

\section{Results}

Table 1 shows the means of the measurements made at the school clinics of the Dental School of UFPE obtained from the peripheral areas (office table) and action (bench) in different shifts. In general, there was a reduction in the levels of as the hours go by; there are statistically significant differences between morning and evening shifts in all clinics, regardless of the measurement site. It was verified that the work shift exerted statistically significant influence $(\mathrm{p}<0,05)$ on the illuminance levels of the peripheral region of clinics A (Kruskal-
Wallis test/Dunn's test, $\mathrm{H}=12.1153$ ); B (Analysis of Variance/Tukey's Test, $\mathrm{F}=12.5947$ ); $\mathrm{C}$ (Analysis of Variance/Tukey's Test, $\mathrm{F}=3.7045$ ). This same result was found for the area of action of clinics A (Kruskal Wallis Test/Dunn Test, $\mathrm{H}=15.9035)$; B (Kruskal-Wallis test/Dunn's test, $\mathrm{H}=13.6772$ ); $\mathrm{C}$ (Analysis of Variance/Tukey's Test, $\mathrm{F}=3.5546$ ). When considering the total period of gauging (morning, afternoon and night), the clinics showed statistically different mean values of illuminance for both the peripheral area (Mann Whitney Test, $p$ $<0.05$ ) and for the area of action (Analysis of Variance / Tukey's test, $\mathrm{F}=38.4798, \mathrm{p}<0.05)$. The highest values were attributed in the peripheral area for clinical C (482,38 Lux) and in the action area for clinical B $(550,88$ Lux $)$, as can be seen in Figure 2. Regarding to the intervention area, mean values of illuminance, with their respective standard deviations $( \pm)$, were 5208.14 Lux for clinical A $( \pm 393.44)$, 6468.21 Lux for B $( \pm 690,55)$ and 6871.11 Lux for C $( \pm 509.17)$. The analysis of variance of the means and the subsequent application of the Tukey's test revealed that there were statistically significant differences between clinical B and clinical B and C ( $F=17.7398$, $\mathrm{p}<0.05)$.

Table I Illuminance means (lux) of the school clinics of the UFPE dentistry graduation, obtained from the peripheral areas (office table) and action (bench) in different shifts*

\begin{tabular}{llll}
\hline $\begin{array}{l}\text { Dental } \\
\text { School } \\
\text { Clinic }\end{array}$ & Shifts & \multicolumn{2}{l}{ Place of measurement } \\
\cline { 3 - 4 } & & Peripheral & Of action \\
\hline \multirow{3}{*}{ A } & Morning & $232,67(12,43) \mathrm{b}$ & $465,03(167,06) \mathrm{a}$ \\
& Afternoon & $219,52(10,08) \mathrm{ab}$ & $281,63(24,47) \mathrm{ab}$ \\
& Night & $180,48(29,59) \mathrm{a}$ & $159,29(25,99 \mathrm{c}$ \\
& Morning & $230,0(10,72) \mathrm{a}$ & $732,03(173,03) \mathrm{b}$ \\
$\mathrm{B}$ & Afternoon & $163,33(10,0) \mathrm{b}$ & $802,24(51,12) \mathrm{b}$ \\
& Night & $154,29(51,34) \mathrm{b}$ & $118,37(19,73) \mathrm{a}$ \\
& Morning & $479,05(31,3 \mathrm{I}) \mathrm{ab}$ & $448,03(32,78) \mathrm{a}$ \\
$\mathrm{C}$ & Afternoon & $505,24(35,27) \mathrm{a}$ & $422,24(29,92) \mathrm{ab}$ \\
& Night & $462,86(19,19) \mathrm{b}$ & $399,42(12,63) \mathrm{b}$ \\
\hline
\end{tabular}

*The values in parentheses represent the standard deviations of the respective illuminance averages. Different letters reveal statistically significant differences when comparing the means of each measurement site in the dental school clinics. 


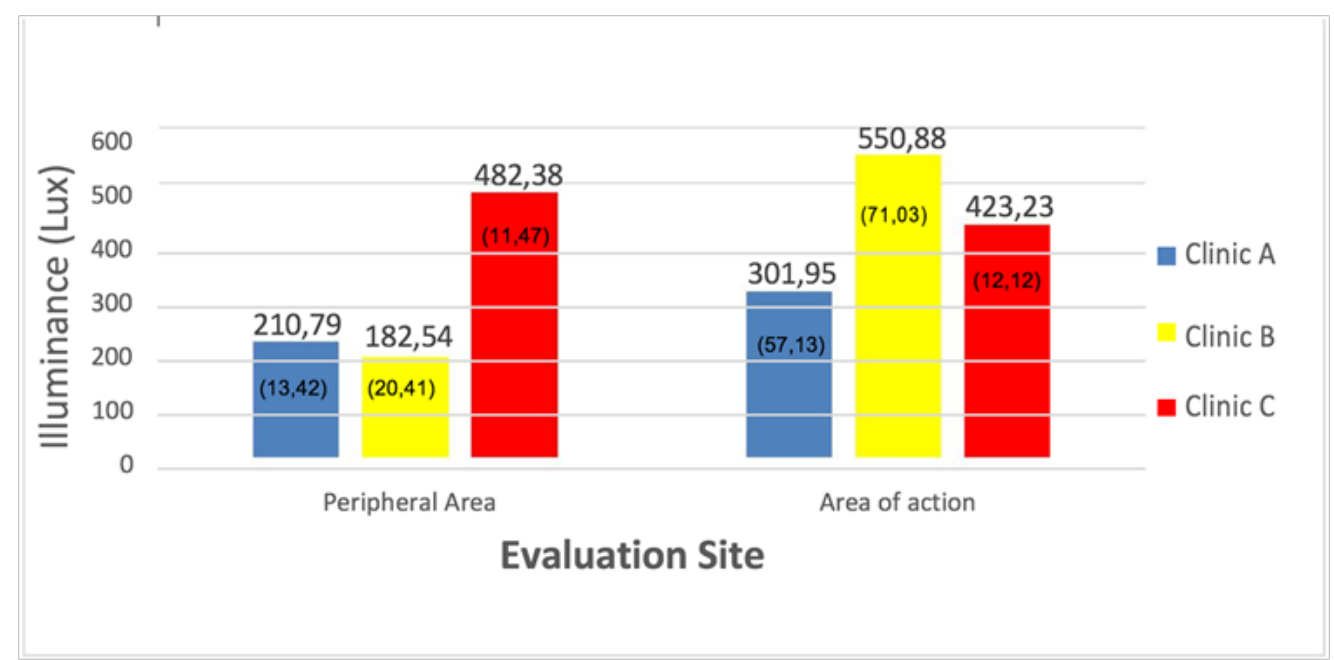

Figure 2 Illuminance means (lux) of the school clinics of the UFPE dental school, obtained from the peripheral areas (office desk) and action (bench). *The values in parentheses represent the standard deviations of the respective illuminance averages.

\section{Discussion}

Environmental ergonomic parameters are often overlooked when planning work environments. Because they are not easily and easily measured, they still represent an under-explored area, but it exerts a great influence on the well-being of the dental surgeon during the execution of his work. The visual well-being represents another point, which deserves attention on the part of the dentists, since the level of illumination interferes directly in the physiological mechanism of the vision and also in the musculature that commands the movements of the eyes, leading with this to the visual fatigue and fatigue Body, since $25 \%$ of body fatigue is related to ocular tension. To avoid this, there must be careful planning of the lighting, ensuring that the object is focused from a comfortable posture ${ }^{4}$ According to NR 17, general illumination must be uniformly distributed and diffused; designed and installed to avoid glare, uncomfortable reflections, shadows and excessive contrasts. ${ }^{5}$ There must be adequate lighting in the environment to improve working conditions, provide greater comfort and adequate productivity. ${ }^{6}$ The results obtained in this research showed reduced values in the illuminance levels as the hours passed, registering statistically significant differences between morning and evening shifts in all clinics, regardless of the measurement site. As a general rule, the dentistry clinic should meet the requirements established by NBR ISO / IEC 8895-1 $\mathrm{ABNT}^{7}$ which indicates the following reference values: 500 lux for the peripheral region; 1000lux for the area of action; 5000 lux for the intervention area. Thus, the results pointed to the peripheral and action areas were below the desired, except for the peripheral region of clinic $\mathrm{C}$ in the afternoon. The peripheral region is characterized as being the office area, whose lighting is necessary for reading and writing. The area of action corresponds to the area adjacent to the patient (benches, equipment), which needs adequate lighting, as it will be the place where the works will develop.

In all UFPE school clinics there are side windows that allow the entrance of natural light into the work environment. Thus, this light had an influence on the illuminance of the peripheral and action regions, since in almost all clinics the luminosity in the night period was statistically inferior in relation to the daytime period. According to Kroeger, ${ }^{8}$ where possible, natural light should supplement artificial light. The presence of natural light as well as help in the psychic accommodation of the patient, offers the ideal condition for the selection of natural tooth colors. For this reason, it is essential that the office has a window next to the dental surgeon's chair that allows the penetration of sunlight. Another fact that may have influenced the reduction of light intensity at night refers to the fact that there are no curtains at the school clinics studied. The windows at night should not appear as dark areas, they should be cleared by the installation of light curtains or special glazing, supported by an irradiation of light from above, so that it does not cause any glare by the luminaires. ${ }^{9}$ In the intervention area, which represents the region of the oral cavity of the patient, whose illumination comes from the dental reflector, the data obtained were shown according to the norms established by ABNT, with averages included in the range of 5000 to 7000 lux. These adequate levels of illumination obtained at all school clinics for the intervention area exert a positive influence on visual acuity (ability to perceive the details), being extremely important, since it allows a fast, precise and efficient action, since the Dentist works inside a cavity filled with anatomical structures that make shadows over each other, making it difficult to evaluate the exact color, shape and depth.

On the other hand, the great difference of illuminance in relation to the area of action (equipment and benches) must be taken into account, because when the operator changes the vision out of the illuminated field of intervention, an aggression to the pupil occurs, due to abrupt Change from light to dark, resulting in discomfort. ${ }^{3,8}$ During the measurements, clinic B had defective bulbs. Possibly this deficiency may have exerted influence on the levels of illuminance found. However, clinics $\mathrm{A}$ and $\mathrm{C}$ had all the lamps in perfect condition. In this way, it is perceived the need of an architectural planning aiming at the addition and/or redistribution of luminaires with the purpose of conferring better working conditions, as well as there should be periodic maintenance of existing luminaires in the environments, to avoid the permanence of lamps Defective. The findings of this study expressed a methodology that sought to minimize potential biases related to operators and the measuring device. Proper referrals will be made so that environmental parameters are adjusted to make dental work spaces more ergonomic. From this perspective, other studies with the same theme become necessary for periodic evaluation, aiming at the achievement of a satisfactory work environment for students, teachers and technicians. 


\section{Conclusion}

The illuminance levels from intervention area of all clinical facilities presented values compatible with the parameters set by Brazilian regulations. On the other hand, the peripheral and action areas were far from ideal. In this way, the need for an architectural planning aiming at the addition and/or redistribution of luminaires with the purpose of providing better working conditions is realized.

\section{Acknowledgments}

None.

\section{Conflicts of interest}

The authors declare that there is no conflicts of interest.

\section{References}

1. Barros OB. PTO: Dental Work Station. Maringá: Dental Press. 2006:238.

2. Saquy JD, Pécora JD, Sobrinho JS. Dental office lighting. Rev Assoc Paul Cir Dent. 2007;48:1467-1471.
3. Garbin AJI, Garbin CAS, Ferreira NF, et al. Illumination in the dental office. Acta Cientifica Venezolana. 2007;58:29-32.

4. Darses F, Falzon P. Collective Design: An Approach to Cognitive Ergonomics. In: Terssac G, Friedberg E, editors. Cooperation and Design. Toulouse: Octares. 1996.

5. Brasil. Ministry of Labor and Employment. NR, Norma Regulamentadora. NR-17 - Ergonomics. 2009.

6. Wee AG, Meyer A, Wu W, et al. Lighting conditions used during visual shade matching in private dental offices. $J$ Prosthet Dent. 2016;115(4):469-474.

7. ABNT. Brazilian Association of Technical Standards. NBR ISSO/CIE 8995- Workplace lighting-Part 1: Interior. London: ABNT; 2013.

8. Kroeger RF, Stevens DE, Vamosi SJ. Designing the dental Office for relaxation. Quint Int. 1986;17:760-775.

9. Simurro SAB, Nicoletti EA, Skarbnik RZ. Stress: satisfaction and quality of life in executives. Revista de psicologia da Vetor Editora. 2000;1(3):18-26. 